\title{
Ovarian dysgenesis associated with an unbalanced X;6 translocation: First characterisation of reproductive anatomy and cytogenetic evaluation in partial trisomy 6 with breakpoints at Xq22 and 6p23
}

\author{
ERIC SCOTT SILLS ${ }^{1,2}$, PHILIP D. COTTER ${ }^{3,4,5}$, KEVIN D. MARRON ${ }^{2}$ \\ LYUDA V. SHKROBOT ${ }^{2}$, HARRIET M.A. WALSH ${ }^{6}$ and RIFAAT D. SALEM ${ }^{1}$
}

\begin{abstract}
${ }^{1}$ Division of Reproductive Endocrinology Research, Pacific Reproductive Center, Irvine, CA, USA; ${ }^{2}$ Division of Reproductive Endocrinology, The Sims Institute/Sims IVF, Department of Obstetrics and Gynaecology, School of Medicine, Royal College of Surgeons in Ireland, Dublin, Ireland; ${ }^{3}$ Department of Pediatrics, University of California San Francisco, San Francisco, CA, USA; ${ }^{4}$ Department of Pathology, Children's Hospital and Research Center at Oakland, Oakland; ${ }^{5}$ Pacific Diagnostics, Irvine, CA, USA; ${ }^{6}$ Marian College, Dublin, Ireland
\end{abstract}

Received May 27, 2011; Accepted August 11, 2011

DOI: $10.3892 / \mathrm{mmr} .2011 .589$

\begin{abstract}
The aim of this study was to describe the clinical and laboratory findings associated with a previously unreported unbalanced X;6 translocation. Physical examination, reproductive history and cytogenetic techniques were used to characterise a novel chromosomal anomaly associated with gonadal dysgenesis. A healthy non-dysmorphic 23 year-old phenotypic female with primary amenorrhea and infertility presented for reproductive endocrinology evaluation. No discrete ovarian tissue was identified on transvaginal ultrasound, although the uterus appeared essentially normal. BMI was $19 \mathrm{~kg} / \mathrm{m}^{2}$. Serum FSH and oestradiol were $111 \mathrm{mIU} / \mathrm{ml}$ and $15 \mathrm{pmol} / \mathrm{l}$, respectively. TSH, prolactin and all infectious serologies were all normal. The karyotype of 46,X,der(X)t(X;6)(q22;p23) was determined following cytogenetic analysis of peripheral blood lymphocytes via fluorescence in situ hybridisation (FISH) with whole chromosome paint for chromosome 6 , and a separate FISH analysis using a $6 \mathrm{p}$ subtelomeric probe. The patient was continued on hormone replacement therapy and underwent genetic counselling; the patient subsequently enrolled as a recipient in an anonymous donor oocyte IVF treatment. Translocations involving autosomes and chromosome $\mathrm{X}$ are rare. While female carriers of balanced X;autosome translocations are generally phenotypically normal, the impact of unbalanced X;autosome translocations can be severe. This is the first known report of an unbalanced translocation involving $\mathrm{X} ; 6$. This abnormality was associated with ovarian dysgenesis, but an otherwise normal female phenotype. From this investi-
\end{abstract}

Correspondence to: Dr Eric Scott Sills, Office for Reproductive Endocrinology Research, Pacific Reproductive Center, 10 Post, Irvine, CA 92618, USA

E-mail: dr.sills@prc-ivf.com

Key words: translocation, $\mathrm{X}$; autosome, ovarian dysgenesis gation, the observed developmental impact of the unbalanced translocation with breakpoints at Xq22 and 6p23 appears to be limited to ovarian failure.

\section{Introduction}

$\mathrm{X}$;autosome translocations are uncommon and are associated with a variable phenotype. In balanced X;autosome females the autosomal segments in the $\mathrm{X}$; autosomal translocations are capable of being inactivated as a result of the spreading of $\mathrm{X}$ inactivation from the adjacent $\mathrm{X}$ chromosome segment (1), thus mitigating any potential adverse phenotype derived from the autosomal imbalance. Despite this non-random $\mathrm{X}$-inactivation, the majority of X;autosome carriers present with abnormal phenotypes including multiple congenital abnormalities, developmental delay, a recognisable X-linked syndrome or gonadal dysgenesis (2).

Unbalanced $\mathrm{X}$; autosome translocation carriers often present with features of Turner syndrome due to $\mathrm{X}$ chromosome monosomies or $\mathrm{X}$ chromosome functional disomy, and frequently more severe phenotypes as a result of autosomal imbalances. In this study, we report a patient with the first known instance of an unbalanced X;autosome translocation resulting in deletion of $\mathrm{Xq} 22 \rightarrow$ qter and autosomal trisomy for $6 \mathrm{p} 23 \rightarrow$ pter.

\section{Case report}

Clinical presentation. A 28 year-old Caucasian female with primary amenorrhea presented with her husband for reproductive endocrinology consultation. Both partners were in good general health and neither were smokers. The female had been on low-dose oral contraceptive pills for several years for cyclic estrogen/progesterone replacement and to induce menses, but had never menstruated spontaneously. On examination, the patient had Tanner IV-V breasts; hirsutism or dysmorphic 

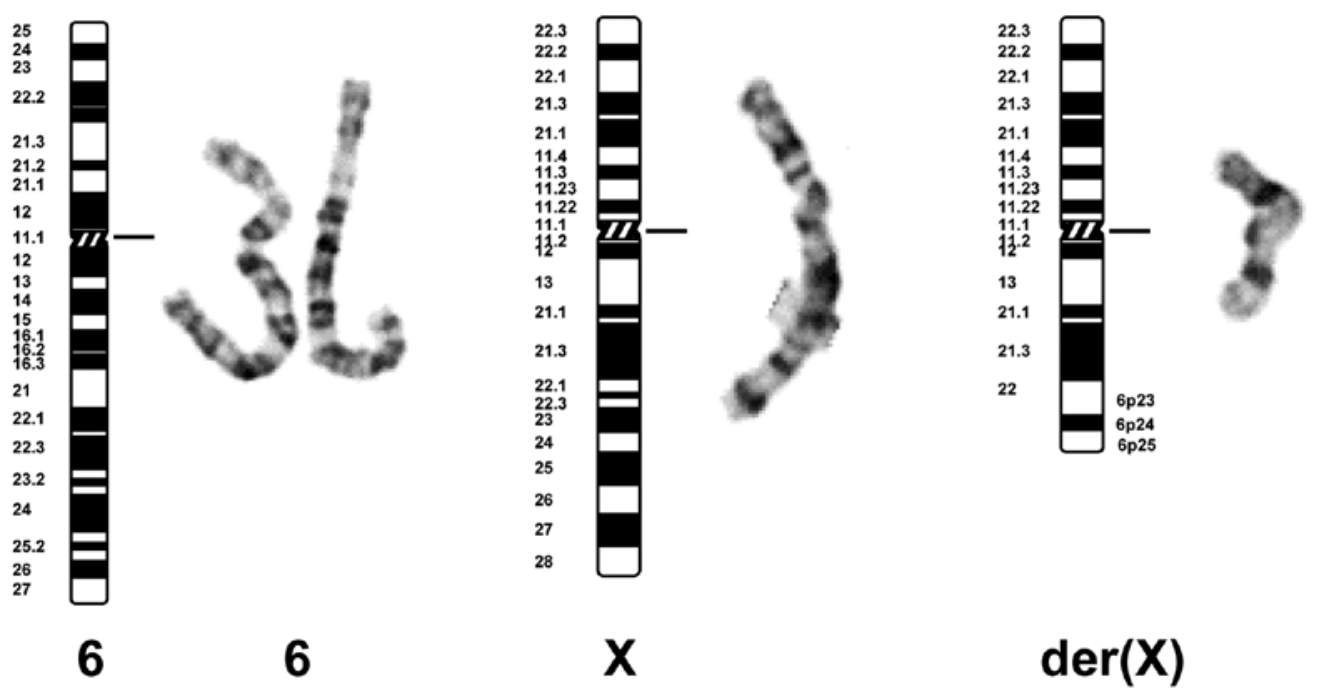

Figure 1. Partial karyotypes and schematics for normal chromosomes 6, $\mathrm{X}$ and the $\operatorname{der}(\mathrm{X})$ chromosome.

A

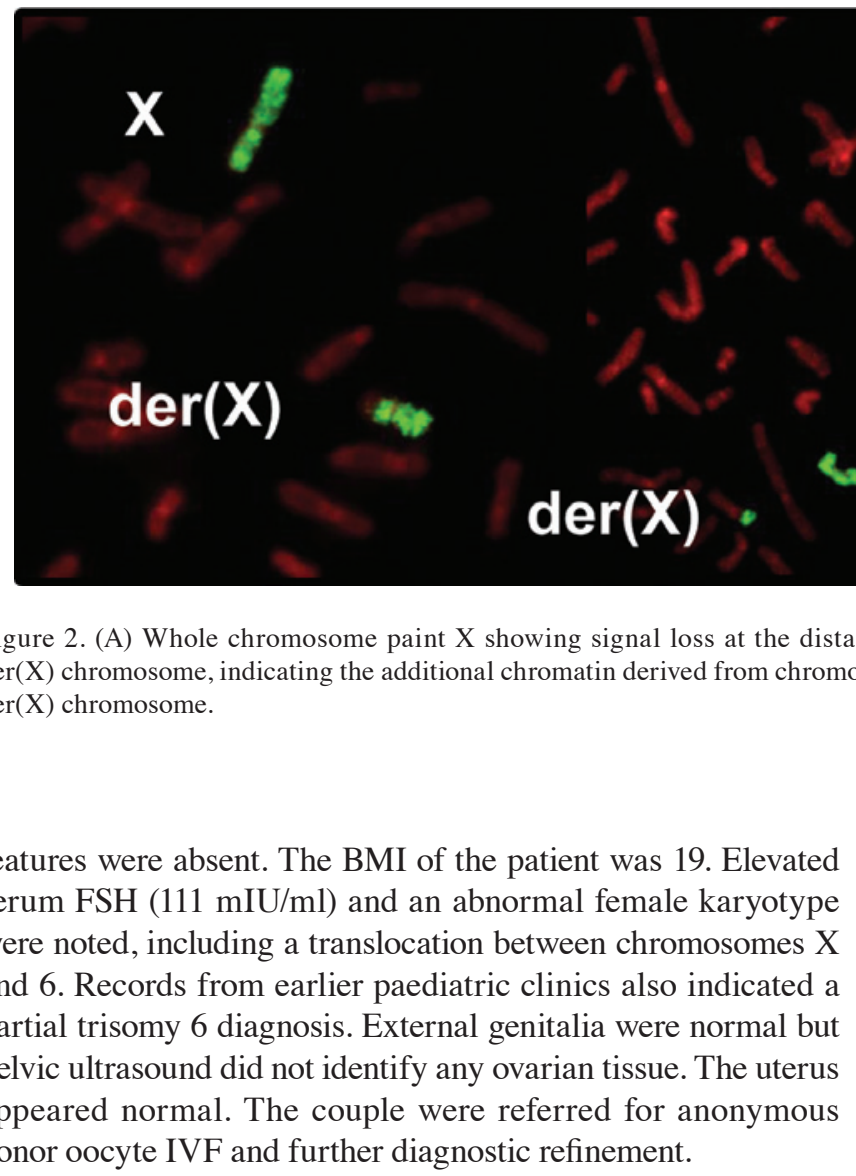

Cytogenetic and FISH analyses. Cytogenetic analysis and GTG-banding from peripheral blood lymphocytes were performed using standard techniques. FISH analysis with whole chromosome paint (wcp) probes for the X chromosome and chromosome 6 (Cambio, Cambridge, UK) and 6p and 6q subtelomere probes (Cytocell, Cambridge, UK) were performed according to the manufacturer's instructions.

Cytogenetic analysis of the proband revealed an abnormal female karyotype with a der(X) chromosome (Fig. 1). FISH analysis with a wcpX showed a signal on the entire normal $\mathrm{X}$ chromosome and a partial signal on the $\operatorname{der}(\mathrm{X})$ chromosome, indicating chromosomal material from another chromosome (Fig. 2A). Additional FISH analysis with a wcp6 identified a signal on the $\operatorname{der}(\mathrm{X})$ chromosome, indicating a chromosome 6 origin for the additional material (Fig. 2B). FISH with subtelomere probes for $6 \mathrm{p}$ and $6 \mathrm{q}$ confirmed the signal for the $6 \mathrm{p}$ probe on the der(X) chromosome (Fig. 2C). From the GTG-banding and FISH analyses, this karyotype was interpreted as 46,X,der(X)t(X;6)(q22;p23); an unbalanced X;autosome translocation resulting in deletion of $\mathrm{Xq} 22 \rightarrow \mathrm{Xqter}$ and trisomy for 6 p23 $\rightarrow$ pter. The paternal karyotype was unavailable, although the proband's mother had a 46,XX karyotype.

\section{Discussion}

That a critical region responsible for normal ovarian function exists on chromosome $\mathrm{X}$ is an idea that gradually coalesced 
from observations of patients with $\mathrm{X}$; autosome translocations and premature ovarian failure (POF). Additional studies showed that Xq13-q26 was a particularly crucial section of chromosome $\mathrm{X}$, since loss or disruption of this region results in severe impairment in ovarian function (3-5). This hypothesis was supported by a review of balanced Xq-autosome translocation where 23 of 36 phenotypic females had POF with a breakpoint between Xq13 and Xq26 (6). However, given the extreme rarity of $\mathrm{X}$; autosome translocations (incidence approximately 1:30,000 live births) (7), the number of cases available for molecular characterisation has been limited.

Our investigation describes a previously unknown X;6 translocation and ovarian dysgenesis, where loss at Xq22 $\rightarrow$ Xqter and trisomy for $6 \mathrm{p} 23 \rightarrow$ pter are associated with complete loss of ovarian function. A review of the published literature revealed one prior instance of $\mathrm{X} ; 6$ translocation associated with POF (8); our case report is believed to be the first description of an unbalanced translocation, however. As the proband manifested no dysmorphic features or developmental delay (presenting clinically in the context of a reproductive endocrinology evaluation secondary to primary amenorrhea/POF), the impact of this unbalanced $\mathrm{X} ; 6$ translocation appears to be limited to ovarian structure and function. A diagnosis of POF of genetic origin was confirmed, and the patient subsequently enrolled in an oocyte donation IVF/embryo transfer program.

Ovarian dysfunction in the setting of this particular unbalanced $X ; 6$ translocation was likely the result of disruption of normal meiosis, or by a position effect. The pattern of POF coexisting with $\mathrm{Xq}$ deletions suggests that the gene for POF1 is localised to Xq21.3-q27 (9) or within Xq26.1-q27 (10), thus, $\mathrm{POF}$ is an unsurprising result of the $\mathrm{Xq} 22 \rightarrow$ Xqter deletion in our patient. By contrast, the clinical consequences of the partial chromosome 6 trisomy would be more difficult to predict. The absence of significant developmental or phenotypic consequences despite trisomy of part of chromosome 6 may be explained by the inactivation of the translocated autosome, since functional trisomy of even a portion of chromosome 6 is typically associated with a grossly abnormal clinical picture $(11,12)$. In cases of unbalanced $X$; autosome translocations where all or part of the translocated autosome is trisomic, a deleterious functional trisomy is avoided only if the translocated autosome is inactivated (13).

In conclusion, this case advances the understanding of $\mathrm{X}$;autosome translocations by presenting clinical and cytogenetic data on a new unbalanced $X ; 6$ translocation. It is believed to be the first description of $\mathrm{Xq} 22 \rightarrow$ Xqter deletion with trisomy for $6 \mathrm{p} 23 \rightarrow$ pter. Notably, the impact of this unbalanced translocation with breakpoints at Xq22 and 6p23 appears to be limited to POF, and the patient has a bright prognosis for pregnancy using oocyte donation and IVF (14).

\section{References}

1. White WM, Willard HF, Van Dyke DL and Wolff DJ: The spreading of $\mathrm{X}$ inactivation into autosomal material of an $\mathrm{X}$; autosome translocation: evidence for a difference between autosomal and X-chromosomal DNA. Am J Hum Genet 63: 20-28, 1998.

2. Waters JJ, Campbell PL, Crocker AJM and Campbell CM: Phenotypic effects of balanced $\mathrm{X}$-autosome translocations in females: a retrospective survey of 104 cases reported from UK laboratories. Hum Genet 108: 318-327, 2001.

3. Sarto GE, Therman E and Patau K: X inactivation in man: a woman with $\mathrm{t}(\mathrm{Xq}-; 12 \mathrm{q}+)$. Am J Hum Genet 25:262-270, 1973

4. Phelan JP, Upton RT and Summitt RL: Balanced reciprocal X-4 translocation in a female patient with early secondary amenorrhea. Am J Obstet Gynecol 129: 607-613, 1977.

5. Summitt RL, Tipton RE, Wilroy RS Jr, Martens PR and Phelan JP: $\mathrm{X}$-autosome translocations: a review. Birth Defects Orig Artic Ser 14: 219-247, 1978

6. Madan K, Hompes PG, Schoemaker J and Ford CE: X-autosome translocation with a breakpoint in Xq22 in a fertile woman and her 47,XXX infertile daughter. Hum Genet 59: 290-296, 1981.

7. Gupta N, Goel H and Phadke SR: Unbalanced X;autosome translocation. Indian J Pediatrics 73: 840-842, 2006.

8. Powell CM, Taggart RT, Drumheller TC, et al: Molecular and cytogenetic studies of an X;autosome translocation in a patient with premature ovarian failure and review of the literature. Am J Med Genet 52: 19-26, 1994.

9. Krauss CM, Turksoy RN, Atkins L, McLaughlin C, Brown LG and Page DC: Familial premature ovarian failure due to an interstitial deletion of the long arm of the X chromosome. N Engl J Med 317: 125-131, 1987.

10. Tharapel AT, Anderson KP, Simpson JL, et al: Deletion (X) (q26.1-->q28) in a proband and her mother: molecular characterization and phenotypic-karyotypic deductions. Am J Hum Genet 52: 463-471, 1993.

11. Villa O, Del Campo M, Salido M, et al: Small supernumerary marker chromosome causing partial trisomy $6 p$ in a child with craniosynostosis. Am J Med Genet A 143A: 1108-1113, 2007.

12. Bart IY, Weemaes CM, Schuitema-Dijkstra AR, Smeets D and de Vries E: Immunodeficiency in a child with partial trisomy $6 \mathrm{p}$. Acta Paediatr. 2011 Feb 7. doi: 10.1111/j.1651-2227.

13. Hall LA, Clemson CM, Byron M, Wydner K and Lawrence JB: Unbalanced $\mathrm{X}$; autosome translocations provide evidence for sequence specificity in the association of XIST RNA with chromatin. Hum Mol Genet 11: 3157-3165, 2002.

14. Walsh AP, Omar AB, Marron KD, Walsh DJ, Salma U and Sills ES: Recipient screening in IVF: First data from women undergoing anonymous oocyte donation in Dublin. Reprod Health 8: 8, 2011. 